\title{
Measurement under pressure of thermoelectric power along the thickness of a thin specimen
}

\author{
Sheela K. Ramasesha and Anii K. Singh \\ Materials Science Division, National Aeronautical Láboratory, Bangalore 560 017, India
}

(Received 14 August 1990; accepted for publication 18 December 1990)

\begin{abstract}
A method of measuring under pressure the thermoelectric power along the thickness of thin specimens is described. This method is useful in measuring thermoelectric power in a direction perpendicular to the cleavage plane of a crystal.
\end{abstract}

The high pressure cell for tungsten carbide opposed anvil setup described earlier' has been used successfully to measure thermoelectric power (TEP) across the phase transitions of a number of solids. ${ }^{2-4}$ The method requires samples approximately $4 \mathrm{~mm}$ long, $1 \mathrm{~mm}$ wide and $0.1 \mathrm{~mm}$ thick and the TEP measured is along the length of the specimen. In this note a method is described to measure TEP along the thickness of the specimen. The method is useful in measuring TEP in a direction perpendicular to the cleavage plane of a crystal.

A pair of tungsten carbide anvils (without any binding rings, $25.4 \mathrm{~mm}$ diameter, $40 \mathrm{~mm}$ length, flat face diameter $12.7 \mathrm{~mm}$ ) powered by a 100 ton hydraulic ram is used to generate pressure. The gasket assembly is shown in Fig. 1. A pyrophyllite gasket $(12.5 \mathrm{~mm}$ o.d., $5 \mathrm{~mm}$ i.d., $0.35 \mathrm{~mm}$ thick) with a closely fitting talc disk at the center is placed on the anvil. A $0.1-\mathrm{mm}$-deep diametric groove is made on the top surface of the gasket. A chromel-alumel thermocouple ( $0.1 \mathrm{~mm}$ diameter), $A_{1}-C_{1}$ is placed in the groove such that the thermojunction, $J_{1}$, is at the center of the talc disk. A specimen measuring approximately $2 \times 2 \times 0.4 \mathrm{~mm}^{3}$ is placed at the center of another pyrophyllite gasket $(12.5 \mathrm{~mm}$ o.d., $5 \mathrm{~mm}$ i.d., $0.4 \mathrm{~mm}$ thick ), and the annular space around the specimen filled with 1:1 volume mixture of epoxy and talc powder. After allowing sufficient time ( $12-24 \mathrm{~h}$ ) for the epoxy to set, the gasket-specimen assembly is thinned to 0.25 $\mathrm{mm}$ by working on both sides on 600 grade emergy paper, such that the specimen surface is exposed on both sides. The gasket-specimen assembly is placed atop the first. The thermojunction, $J_{1}$, comes in contact with the bottom surface of the specimen. A third gasket with a talc disk at the center, dimensions being the same as that of the first gasket, was placed atop the second gasket. A thermocouple, $A_{2} C_{2}$, was placed between the second and third gasket, with the thermojunction, $J_{2}$, in contact with the top surface of the specimen. A temperature gradient along the thickness of the specimen is set up with the help of a $5 \mathrm{~W}$ heater wound around the lower anvil. The temperature difference up to 2 $\mathrm{K}$ can be set up between the two faces of the sample. A larger temperature difference is difficult to achieve because of good thermal contact (through the gasket) between the anvils. The specimen temperature can be varied between room temperature and $100{ }^{\circ} \mathrm{C}$ by placing a tubular heater (not shown in Fig. 1) around both the anvils. At a higher temperature the epoxy in the epoxy-talc mixture around the specimen softens and often results in a blowout of the gasket. Temperatures below room temperature, down to $77 \mathrm{~K}$, have been achieved by immersing the anvils in liquid nitrogen. The voltages $\Delta E_{A A}$ and $\Delta E_{C C}$, respectively, between two alume $\left(A_{1}-A_{2}\right)$ and two chromel $\left(C_{1}-C_{2}\right)$ leads are measured using a Keithley-196 digital multimeter. For higher precision nanovolt potentiometer ( $7555-\mathrm{K}-5$, Leeds \& Northrup) can be used. The TEP of the specimen, $Q_{s}$, is calculated using the following relation:

$$
Q_{S}=\left(Q_{A}-r Q_{C}\right) /(1-r),
$$

where $Q_{A}$ and $Q_{C}$ are, respectively, the absolute TEP of alumel and chromel, and $r=\Delta E_{A A} / \Delta E_{C C}$. Though we have used dc-voltage measurement to obtain TEP, in principle more sensitive techniques that use computers can be inter. faced with this cell. ${ }^{5-8}$ However, ac-voltage measuremente cannot be used here due to the large mass of the anvils.

The load applied on the anvil was calibrated in terms 0 . specimen pressure by the procedure discussed elsewhere. The highest pressure reached with this setup was $6 \mathrm{GPa} . \mathrm{Th}^{\text {* }}$ performance of the high pressure cell was assessed by mes. suring the TEP of mercury selenide as a function of pressure Since the zinc-blende-to-cinnabar transition ${ }^{9,10}$ is sluggisin the experiments were done at $90^{\circ} \mathrm{C}$ by heating the anvilf with a tubular heater. Even at this temperature, transitio took $5 \mathrm{~h}$ for completion. The variation with pressure of TE indicated by the present data (Fig. 2) agrees well with the
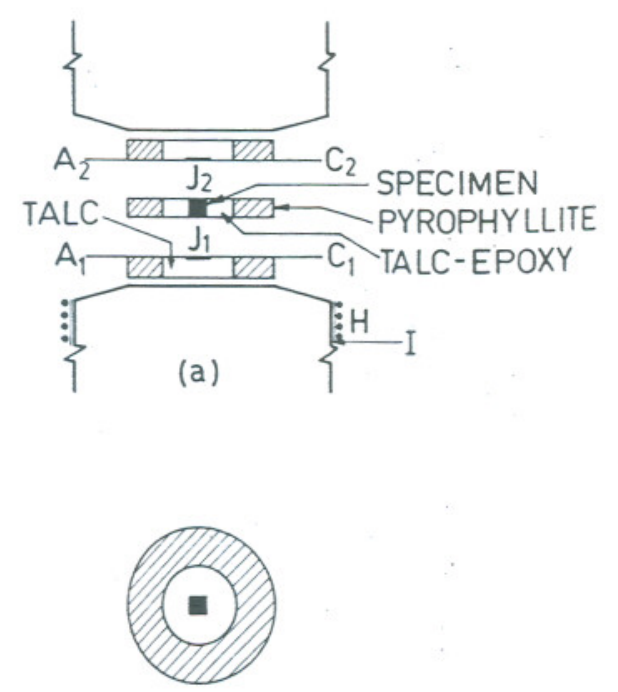

(b)

FIG. 1. (a) Schematic diagram of the high pressure cell. $J_{1}, J_{2}-$ ther couple junctions. $A_{1} C_{1}, A_{2} C_{2}$-thermocouples. $H$-heater, $I$-insuls (b) Pyrophyllite gasket containing the sample set in talc epoxy. 




G. 2. TEP vs pressure of $\mathrm{HgSe}$ at $90^{\circ} \mathrm{C}$. observed in an independent measurement with piston-cylinder apparatus. ${ }^{\prime \prime}$

The authors would like to thank Dr. P. S. Gopalakrishnan for providing the crystals.

\footnotetext{
'A. K. Singh and G. Ramani, Rev. Sci. Instrum. 49, 1324 (1978).

${ }^{2}$ G. Ramani and A. K. Singh, Solid State Commun. 29, 583 (1979).

${ }^{3}$ C. Divakar, M. Mohan, and A. K. Singh, Solid State Commun. 41, 333 (1982).

${ }^{4}$ G. Ramani, C. Divakar, and A. K. Singh, Phys. Rev. B 35, 1440 (1987).

${ }^{5}$ V. Shubha and T. G. Ramesh, High Temp.-High Pressures 18, 311 (1986).

'P. C. Eklund and A. K. Mabatah, Rev. Sci. Instrum. 48, 775 (1977).

${ }^{7}$ C. Wood, D. Zoltan, and G. Stapfer, Rev. Sci. Instrum. 56, 719 (1985).

${ }^{8}$ S. S. Roberts, S. M. Rabinovich, Y. H. Shing, N. T. Tran, and J. Y. Josefowicz, Rev. Sci. Instrum. 57, 276 (1986).

${ }^{9}$ P. W. Bridgman, Proc. Am. Acad. Arts. Sci. 74, 24 (1940).

${ }^{10}$ A. Ohtani, T. Seike, M. Motobayashi, and O. Onodera, J. Phys. Chem. Solids 43, 627 (1982).

"T. G. Ramesh and V. Shubha, J. Phys. C 15, 6193 (1982).
} 